\title{
CIF section opposes expansion of natural gas processing plant
}

A major natural gas processing plant in western Alberta, Aquitaine Company of Canada Ltd., had applied to the Energy Resources Conservation Board of Alberta for expansion. The Rocky Mountain Section of the CIF was concerned about the potential damage to the surrounding forest regions from fume damage and submitted a brief to the Board hearing. Opposition to the application was also filed by the Alberta Fish and Game Association. The main part of the CIF brief was as follows:

1/ We do not believe that $\mathrm{SO}_{2}$ discharge levels being proposed by the applicant will consistently meet even the current Alberta regulations, which we believe in some instances to be too high ${ }^{1}$, because:

a/ The calculations assumed a windspeed of 15 mph while actual windspeed, from the Baseline Tower (the nearest weather observation post), averages about $6.5 \mathrm{mph}$. What will happen on calm days; or on any day that wind is less than $15 \mathrm{mph}$ ?

b/ We can find no reference in the specifications or accompanying letters, that consideration has been given to the undulating topography which can be expected to result in areas of excessive concentration of effluent gasses.

c/ We can find no consideration of the influence of forest cover upon air turbulence and mixing. The generally more calm air beneath the tree canopy may lead to concentration of lethal (to vegetation) proportion.

d/ We can find no consideration of the fact that the Gulf Strachan plant is only 8 miles away, and of the resulting increase in ambient $\mathrm{SO}_{2}$ when the wind is from the N.W. Presumably that plant is also operating under conditions allowing up to the maximum acceptable $\mathrm{SO}_{2}$ levels.

e/ We can find no consideration of the "pluming" effect on vegetation in which the gasses from the flue can, under certain meteorological conditions, remain unsatisfactorily diluted, travelling in a plume for many miles and touching down to ground level at lethal (to vegetation) $\mathrm{SO}_{2}$ concentration.

f/ We are not confident that plant operating efficiency can be maintained to recover $96 \%$ of the sulfur during start-up or $98 \%$ thereafter. On past performance at other similar plants, most notably near Pincher Creek, operating efficiencies were dramatically reduced, especially during winter months. At that, the combined sulfur effluents of both the plants near Pincher Creek were about one quarter the proposed effluent of the applicant during start-up.

\footnotetext{
'Specifically, exposure to $\mathrm{SO}_{2}$ at levels less than $0.1 \mathrm{ppm}$ for 4 hours induced acute injury to new needles of white pine, Pinus strobus (Costonis, 1971, Phytopathology 61: 717-720). While there appears to be no published tolerance levels for lodgepole pine, Pinus contorta var. latifolia, or for other major species in the vicinity of the applicant's site, we think that $\mathrm{SO}_{2}$ levels should not be allowed to exceed those levels for which there is documented evidence of damage to forest vegetation.
}

g/ We note that emergency flaring facilities are provided for the total plant inlet. In such a circumstance, presumably the total $\mathrm{SO}_{2}$ emitted would be in the order of 8,500 long tons with a resultant concentration at ground level in the order of $10 \mathrm{ppm}$.

2/ In this area of high timber values, high recreational attraction, and high and increasing utilization for multiple uses; precautions should be exercised beyond those required by the current Alberta regulations. There is a large amount of literature that documents $\mathrm{SO}_{2}$ damage to foliage of trees and associated understory vegetation. The onus should be on the applicant to show that levels of $\mathrm{SO}_{2}$ resulting from expanded operations will not injure the surrounding forest community.

3) The Clean Air Act of the Government of Canada has provisions for certain regulatory powers. Because sulfur arising from processing of natural gas in Alberta has been detected as far distant as the Pacific Ocean it seems highly likely that such processing may involve Federal guidelines. Has the applicant made enquiry on this matter to the appropriate Federal agency?

4/ In the light of the difficulties experienced by residents of the Pincher Creek area in obtaining legal redress for damages suffered, we believe definite legal guidelines should be publicized before applications of this type are considered in final submission. Specifically, we wish to know how a citizen of Alberta, if deprived of income or his normal enjoyment of the forests of the region containing the Ram River plant, might proceed to obtain compensation for his loss, should such occur.

The Board considered that the main issues were: conservation features, sulphur dioxide concentration standard, pollution control features, and possible mercury contamination of the surrounding environment. Excerpts from the Board's decision pertaining to the CIF brief were:

Conservation. The Board is of the opinion that the proposed sulphur recovery levels are satisfactory provided the unrecovered sulphur is disposed of in an acceptable manner. It believes that operation for a one-year period at the lower $96 \%$ recovery level would be acceptable since active development towards improving sulphur recovery technology would be pursued by the applicant. The Board is of the opinion that $94 \%$ is a reasonable recovery for a well-equipped two-stage Claus plant and accepts the applicant's view that $98 \%$ recovery can be maintained with a two-stage Claus plant followed by a Sulfreen unit. The Board recognizes that recoveries lower than the proposed levels could occur during the plant start-up period or during plant upsets and is of the opinion that if this occurs the plant operator should reduce plant throughput to maintain sulphur dioxide emission rates below an acceptable maximum.

Sulphur dioxide concentration standard. The 
Board appreciates the view of the Institute but accepts the standards of the Department of the Environment. The Board notes that the applicant has consulted the Department of Lands and Forests of the Government of Alberta and the Department of Fisheries and Forestry of the Government of Canada regarding proposed studies to assess the effect of the emissions on the plant and animal life in the plant vicinity and expects that the present standards would be modified if the proposed studies or any directly relevant observations indicated any adverse effect of the emissions on the environment.

The Board will require that Aquitaine comply with the standards established for both the agricultural and forested areas in the plant vicinity.

Pollution control. The Board recognizes that under certain meteorological conditions, concentrations of sulphur dioxide higher than those calculated could occur but is of the opinion that the higher concentrations would only occur under severe atmospheric conditions which happen infrequently and that more than $95 \%$ of the time observed concentrations would be less than those calculated.

In light of the calculations, which indicate that sulphur dioxide concentrations could exceed the Provincial standard under certain conditions, the Board is of the opinion that the proposed sulphur dioxide emission rates should only be permitted with operation of an adequate sulphur dioxide monitoring network in the plant vicinity to ensure that the sulphur dioxide concentration standard is not exceeded.

Legal redress. The Board is not prepared to present a detailed view on the Institute's suggestion that legal guidelines be described for individual compensation in the event of damages. The Board believes that should damage occur compensation could be ascertained in the normal way, i.e. by agreement among the parties or through the courts.

Decision. The Board approves the application subject to the condition that Aquitaine install and maintain four monitoring stations for the detection of sulphur dioxide in the plant vicinity at locations to be approved by the Board and the Department of the Environment. The measured sulphur dioxide concentrations are to be transmitted continuously to the plant and Aquitaine will be required to reduce plant through-put whenever the measured concentration exceeds $0.2 \mathrm{ppm}$ averaged over a $15-$ minute period, to maintain the concentrations within this limit. The Board will also require that ten additional exposure cylinder stations be installed.

The regulations required to be fulfilled by the Company relating to the emission, detection and monitoring of gaseous effluents are more restrictive than envisioned by the Company in their submissions. In particular, increased numbers of monitoring stations are required and a very important reduction is made to the $\mathrm{SO}_{2}$ levels, from $0.3 \mathrm{ppm}$ to $0.2 \mathrm{ppm}$ for any given 15-minute interval.

\section{Automated log sorter}

Automation has invaded the sawmill industry and CAE Machinery Ltd., of Vancouver, is leading the attack to increase productivity in Western Canada and, more recently, the United States.

This Canadian company, a subsidiary of CAE Industries Ltd., Montreal, develops and manufactures electronically-controlled log handling and log sorting machinery and systems for the sawmill industry.

Its latest order, placed recently by Weyerhaeuser Co., Tacoma, Wash., is for a $\$ 170,000$ system for the company's new hardwood log merchandising plant at Wright City, Oklahoma.

The log sorter system will take logs from a deck, where they are unscrambled from an untidy pile and fed onto a conveyor system one at a time. The sorter will operate in conjunction with a log merchandiser, consisting basically of two log trim saws which cut logs up to $60 \mathrm{ft}$ long into shorter lengths.

Short lengths of poor quality wood will be sent directly to a chipper, while the merchantable logs are directed by the log sorter into bins according to their size. These logs are removed by mobile equipment and delivered to the sawmill at the appropriate time.

As the supply of merchantable logs from the trim saws is unpredictable, surges will occur, sometimes at a higher rate than the capacity of the sorting equipment. To accommodate these surges, the system includes a special rollcase and shear system which will bring the logs under control for feeding across the decks to the unscrambler.

CAE's log handling and log sorting systems are custom designed to each mill requirement, using basic modules developed from the designs of Hammars, the Swedish manufacturers for which CAE Machinery is exclusive representative in North America.

The components of a complete CAE system are:

1/ Log decks and unscramblers which automatically segregate an untidy pile of logs into a flow which is delivered to a conveyor system one log at a time.

2/ Dividing sections which recognize that cutoff saws, barkers and other machinery often operate at slower speeds than the delivery system, which can provide logs at a rate of between 15 and 20 per minute. The flow of logs is therefore divided into two lines for barking and cut-off purposes.

3/ Merging sections which return the divided flow into a single line.

4/ Sorting systems, consisting of a longitudinal conveyor on which the logs are electronically scaled for minimum, maximum and, in some cases, intermediate diameters. The minimum diameter is selected, the length measured, the mid-point of the log determined and the required data is displayed digitally. The operator can add further inputs such as species and grade, and can over-ride the measured data if necessary. 